\title{
A cost-analysis study of using adult red cell packs and Pedi-Packs in newborn intensive care units in Southern Iran
}

\author{
Sezaneh Haghpanah', Shima Miladi², Ali Zamani ${ }^{3}$, Ali Mohammad Keshtvarz Hesam Abadi², Marjan Gholami ${ }^{2}$ \\ and Maryam Gholami ${ }^{*}$ (I)
}

\begin{abstract}
Background and objective: Saving blood products is an important public health issue especially in developing countries with limited financial resources. We aimed to suggest a new hypothetical model to make a change in the current blood transfusion policy in the newborn intensive care unit (NICU) to reduce wastage of blood supplies as well as the risk of exposure to multiple donors.

Methods: In this cross-sectional study, all transfused neonates $(n=70)$ who were admitted to NICU of Nemazee Hospital, a tertiary referral hospital in Southern Iran, were evaluated between March and June 2019. Based on the information of neonates' transfusion during this study period and determined transfusion indices, a specific pediatric pack was suggested and the related total costs per transfusion, as well as the donor-exposure rate of the hypothetical and the current transfusion method, were compared.

Results: Considering the mean number of transfusions per neonate: 4 and mean volume of transfused packed red cells: $20 \mathrm{ml}$ per transfusion, the cost-analysis of pediatric and the adult pack was presented. Arithmetically, we proved a higher total cost per transfusion for using adult pack comparing to pediatric pack. Additionally, using a pediatric pack set leads to a $24 \%$ reduction in RBCs wastage per transfusion and a $68.13 \%$ reduction in donor-exposure rate.

Conclusions: The assignment of a dedicated pediatric pack for neonates will be able to improve the cost-effectiveness by a substantial reduction in donor-exposure rate and blood wastage. This finding should be taken into consideration to generate economic growth and make improvements in child health status.
\end{abstract}

Keywords: Cost, Neonate, Newborns intensive care unit, Transfusion practice, Donor, Exposure

\section{Introduction}

Despite carrying out some effective strategies such as micro methods blood sampling and autologous placental blood transfusion practice [1-3] to tackle blood loss in the Newborn intensive care unit (NICU), newborns are highly exposed to blood loss and anemia caused by repeated diagnostic phlebotomies [4, 5]. Therefore,

\footnotetext{
*Correspondence: ghomresearch5@gmail.com

${ }^{2}$ Clinical Research Development Center, Nemazee Hospital, Shiraz University of Medical Sciences, Shiraz, Iran

Full list of author information is available at the end of the article
}

multiple small-volume transfusions are often required to deal with this issue. Subsequently, exposure to multiple donors in red blood cells (RBCs) transfusion practice causes concerns about the risk of transmitted infections [6] as well as the hazard of respiratory distress syndrome, bronchopulmonary dysplasia, retinopathy of prematurity, and necrotizing enterocolitis $[7,8]$. To reduce the exposure rate, developed countries have established some effective transfusion methods employing each blood donation for a particular newborn [7-16], such as using the programs with the technology of extending the RBCs 
stored up to 35-42 days by use of a sterile connection device. In this method, an appropriate volume is transferred by gravity into connected satellite packs whenever transfusion is required. [9, 14, 17-23].

On the other hand, using this program leads to reduce the rates of wastage of blood units compared to using RBCs stored up to $<5$ or 7 days due to reserve and use of blood for more than one transfusion from the same donation unit [7, 15-17].

In the literature search, we did not find any document on the use of specific pediatric blood bags such as pediatric frozen red cell packs (Pedi-Packs) in Asian countries. However, the reported utilization rates reveal the lack of an optimal well-defined RBC transfusion method in this region as well [24-26]. Up to our knowledge, in Iran, we have no specific pediatric blood bag at present. Therefore, routine adult packs of fresh red cells $(<5$ or 7 days of storage) are utilized for premature neonates and infants traditionally [27-29]. Consequently, due to small-blood volume consumption per transfusion, it not only results in multiple donors exposure but also causes wastage of a large number of blood supplies, as the proportion of $34.7 \%$ and $93 \%$ RBCs wastage have been reported in NICU and surgery units in different centers in Iran [30, 31].

Single donor program is a remarkable strategy to achieve a cost-effective method of neonatal transfusion, as a saving of $\$ 0.5$ and $\$ 5.54$ per transfusion were reported in two various studies, [18, 21]. Furthermore, assigning Pedi-Packs as a single donor program using at least 4 satellite packs for up to 35-42 days stored RBCs was reported as a safe, convenient, and effective method for transfusion in neonates in several other cost-effectiveness studies as well $[9,14,17,19,20,23]$.

Since we do not have any specific transfusion method for newborns and infants currently in Iran, we decided to notify the health policymakers not only in Iran but also in other developing countries with a similar strategy of this major health concern. Therefore, this study was designed to compare the donor exposure rates and the total cost of the hypothetical usage of Pedi-Packs with the routinely administered adult RBCs packs for neonates in NICU.

\section{Methods}

\section{Subjects}

In this cross-sectional study, medical charts of all neonates who were admitted to NICU of Nemazee Hospital, a tertiary referral hospital in Shiraz, Southern Iran were evaluated between March and June 2019. All newborn babies who received blood transfusion during 3 months of the study $(\mathrm{n}=70)$ were considered as our study population. Based on the pilot study and estimating the wastage percentage ( $\mathrm{p}=92 \%), 34$ cases were calculated as the least acceptable sample size for this study.

The study protocol was approved by the Ethical Committee of Shiraz University of Medical Sciences. (ID =IR. SUMS.REC.1398.995).

Blood Bank (BB) records of all participants were reviewed. Required information consisted of age, sex, weight, cause of admission, number of days stay in NICU, number of transfused packed red cell units $(250 \mathrm{ml})$ and, the time interval between the first and the last transfusion for each neonate. Afterward, we calculated the mean number of transfusions and donor-exposure rate per neonate, as well as the mean volume of wasted RBCs per transfusion.

\section{Current transfusion practice}

An adult RBCs pack of $250 \mathrm{ml}$ fresh red cells stored with $<7$ days, plasma reduced, CMV antibody-negative blood of the neonate's $\mathrm{ABO}$ and $\mathrm{Rh} \mathrm{D}$ group are requested and the cross-matching for each neonate requiring transfusion in the NICU are performed by BB. Small-volume blood is utilized for the first transfusion and if more transfusion is required after the expiry date of the first unit, a second blood unit will be used, and the remains of the first one is will be discarded.

\section{Hypothetical single donor exposure program}

A Pedi-Pack set of fewer than 7 days old will be requested from the $\mathrm{BB}$ for each neonate requiring transfusion in the NICU. This set is leucocyte depleted (mean leucocyte count $2 \times 10^{6} /$ unit after filtration) which is prepared by the BB using a Sepacell R-500 filter in conjunction with a Sterile Connecting Device to preserve a 35-day shelf life for dedicating to one neonate. However, this duration can be extended to 42 days without adverse effects on $\mathrm{pH}$, hematocrit, and potassium concentration of the stored blood [32, 33]. So, we can reserve it for each neonate up to our estimated time interval of transfusions as an expiry date $[14,23]$. So, whenever transfusion is required, an appropriate blood volume from the labeled donation main unit is transferred into a satellite bag and supplied without further compatibility testing.

\section{Definition of blood transfusion costs}

The total costs of the suggested Pedi-Pack and routine adult RBCs pack were compared arithmetically. For this purpose, we specified the total cost (TC) per transfusion for each of the two methods (Table 1) which consist of two components: acquisition RBCs costs and wasted resources cost per transfusion. The first component includes two subgroups: the first subgroup contained handling hospital blood bank's cost (HC) that is administrative activities associated with handling blood products 


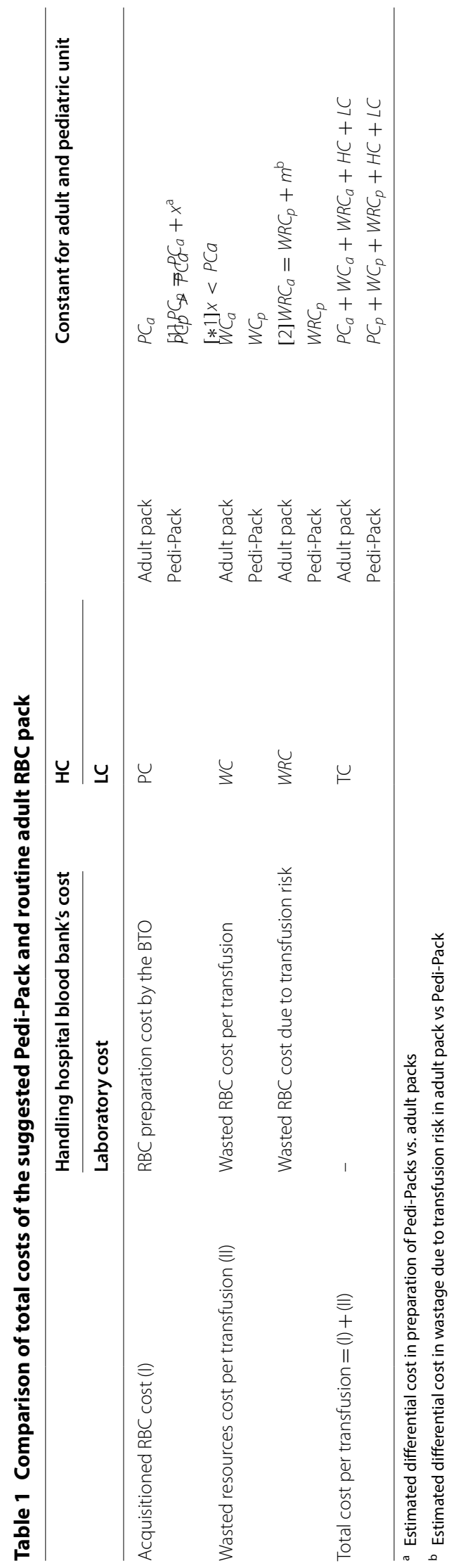


as well as laboratory tests (LC) that both of them are performed by the hospital blood bank and are considered the same for both Pedi-Pack and adult pack; the second subgroup is defined as RBCs preparation cost (PC) which is different between the two methods as much as " $\mathrm{x}$ " and is related to blood the administration equipment used and the preparation process by the Blood Transfusion Organization (BTO). Moreover, the second component of the TC is the wasted resources cost consisting of the wasted $\mathrm{RBCs}$ cost (WC) that is the difference between the two methods as much as "f" and calculated by the wasted volume of packed RBCs multiplying in the final acquisitioned RBCs cost $(\mathrm{HC}+\mathrm{LC}+\mathrm{PC})$ of one ml packed RBCs in each method. Another subgroup of the wasted resources is the transfusion risk cost (WRC) which is different between Pedi-Pack and adult pack as much as " $\mathrm{m}$ " (Table 1) [18, 34].

\section{Statistical analysis}

Data analysis was performed using Statistical Package for the Social Sciences (SPSS) software version 18 (SPSS Inc., Chicago, IL, USA). Descriptive information was presented as mean, standard deviation, median, frequency, and percentage. Subsequently, a cost comparison between two methods considering determined transfusion indices was done arithmetically.

\section{Results}

Demographic data and clinical characteristics of the neonates are presented in Table 2. The mean gestational age, birth weight of the neonates, and the number of days stay in NICU were $33.24 \pm 2.52$ (range 27-39) weeks, $2081 \pm 680$ (range 760-3800) gram, and 19.08 \pm 18.04 (range 1-84) days, respectively, including 39 males (56\%) and 31 (44\%) females. Thirty-three (47\%) had singleevent (or multiple transfusions in one day) and 37 (53\%) of the study population had multiple-event transfusions on different days. The most common clinical diagnosis on admission was congenital heart disease (8\%), necrotizing enterocolitis (5.6\%), and sepsis (2.8\%).

The details of packed RBCs consumption and wastage using adult packs in NICU in the study period are described in Table 3. The total number of adult packs that were used in this duration was 221 , while the total number of transfusions was 250, indicating that 29 units were shared amongst the neonates in this period. Moreover, the mean volume transfused packed red cells was $20 \mathrm{ml}$ per transfusion and $71.42 \mathrm{ml}$ per neonate during admission.

Table 2 Demographic data and clinical characteristics of the study population

\begin{tabular}{|c|c|}
\hline Variables & Mean $\pm s d(\min -\max )$ \\
\hline Gestational age (week) & $33.24 \pm 2.52(27-39)$ \\
\hline Birth weight (gram) & $2081 \pm 680(760-3800)$ \\
\hline \multirow[t]{2}{*}{ Number of days stay in NICU (day) } & $19.08 \pm 18.04(1-84)$ \\
\hline & (\%) $\mathrm{N}$ \\
\hline \multicolumn{2}{|l|}{ Gender } \\
\hline Male & (56) 39 \\
\hline Female & (44) 31 \\
\hline \multicolumn{2}{|l|}{ Clinical diagnosis } \\
\hline Hyper bilirubinemia & (2) 5 \\
\hline Metabolic disorder & $(1.2) 3$ \\
\hline Congenital heart disease & (8) 20 \\
\hline Prematurity & $(1.2) 3$ \\
\hline Anemia & (2) 5 \\
\hline Necrotizing enterocolitis & (5.6) 14 \\
\hline Sepsis & $(2.8) 7$ \\
\hline Imperforated anus & $(1.2) 3$ \\
\hline Ileus & $(0.4) 1$ \\
\hline Respiratory distress syndrome & $(1.2) 3$ \\
\hline Nephrotic syndrome & $(0.4) 1$ \\
\hline Tracheoesophageal fistula & (0.8) 2 \\
\hline Developmental failure & (0.8) 2 \\
\hline Sacrococcygeal teratoma & $(0.4) 1$ \\
\hline
\end{tabular}


Table 3 Red cell consumption and wastage based on the routinely used transfusion practice during the study period

\begin{tabular}{ll}
\hline Variables & $20(14)$ \\
\hline Mean (median) duration between the first and the last transfusion (day) & 221 \\
Total number of the adult packs used & 250 \\
Total number of transfusions & $221 / 70=3.16$ \\
Mean exposure to donor per neonate & $100-(100(1 \times) / 3.16)=68.13 \%$ \\
Percent of reduction in exposure to donor per neonate & $250 / 70=3.57$ \\
Mean transfusion number per neonate & 4 \\
Number of satellite packs based on the mean transfusion number per neonate & $250 / 221=1.11 \mathrm{ml}$ \\
Mean transfusion number per unit & $5000 \mathrm{ml}$ \\
Total Volume of transfused RBCs & $5000 \mathrm{ml} / 250=20 \mathrm{ml}$ \\
Mean volume of transfused RBCs per transfusion & $3.57 \times 20 \mathrm{ml}=71.42 \mathrm{ml}$ \\
Mean volume of transfused RBCs per neonate & $250 \times 230 \mathrm{ml}=57,500 \mathrm{ml}$ \\
Total volume of wasted RBCs & 250 \\
\hline
\end{tabular}

Mean exposure to donor per neonate related to Pedi-Pack $=1$

In our Pedi-Pack model, we suggest a total capacity of $250-\mathrm{ml}$ packed red cells which are closed to the adult pack used, with 4 empty satellite packs also allowing up to 4 separate transfusions to be given based on the specified mean number of transfusion per neonate: 3.57 (nearly 4) during hospitalization in NICU. In the other words to simplicity in the further calculation, we can assume a pedi-pack set with 4 satellite packs each containing $62.5 \mathrm{ml} \mathrm{RBCs}(250 \mathrm{ml} \div 4)$ constantly attached.

Also, since the mean volume of transfused RBCs per transfusion was calculated as $20 \mathrm{ml}, 62.5-\mathrm{ml}$ satellite packs can support the neonatal requirement per one transfusion.

Also, the expiration date of the Pedi-Pack set is considered at least 20 days based on the average time interval between the first and the last transfusion in the evaluated neonates.

Then, blood wastage based on using this model was calculated and compared with the volume of blood wastage using current transfusion practice in NICU (Table 4). The volume of wasted red cells per transfusion was determined $230 \mathrm{ml}$ using adult pack compared to $42.5 \mathrm{ml}$ using Pedi-Pack owning to mean volume of transfused RBCs per transfusion: $20 \mathrm{ml}$ and considering that each sub-pack pack is used only once.

In the next step, we compared the total cost per transfusion between the two methods (Table 1).

As mentioned above, components of $\mathrm{HC}$ and $\mathrm{LC}$ are equal in both methods, so the differences between the total costs of Pedi-Pack and adult pack arise from variations in PC, WC, and WRC.

It seems that PC in Pedi-Pack is more than an adult pack that we considered this difference as much as " $x$ ", Eq. (1) $\left(P C_{p}=P C_{a}+x\right)$, ["1] $(x<P C a)$. The estimated values of the $W C_{a} W C_{p}$ and are calculated as demonstrated in Eq. (2) which resulted in the Eq. (3) $\left(W C_{a}=W C_{p}+f\right)$ whereas the "f" value was specified as the differential cost in the wasted RBCs. Afterward using Eqs. $(1,3)$, and (4) $\left(W R C_{a}=W R C_{p}+m\right)$, we were able to prove that the $T C_{a}$ can be higher than the $T C_{p}$, if and only if the burden cost of purchasing dependent on Pedi-Pack $(x)$ is lower than the total burden costs of wasted resources related to adult pack $(f+m)($ Eq. $(6)$.

Table 4 Comparison of RBCs wastage between the routine (adult pack) and new suggested transfusion practice (PediPacks) for neonates

\begin{tabular}{ll}
\hline Volume $\mathbf{m l}(\%)$ & \\
\hline Volume of wasted RBCs per transfusion $^{\mathrm{a}}$ & \\
Adult pack $250 \mathrm{ml}$ & $250-20=230 \mathrm{ml}(230 \mathrm{ml} / 250 \mathrm{ml}=92 \%)$ \\
Pediatric pack $250 \mathrm{ml}$ & $62.5-20=42.5 \mathrm{ml}(42.5 \mathrm{ml} / 62.5 \mathrm{ml}=68 \%)$ \\
volume of wasted RBCs per neonate ${ }^{\mathrm{a}}$ & \\
Adult pack $250 \mathrm{ml}$ & $4 \times 230 \mathrm{ml}=920 \mathrm{ml}$ \\
Pediatric pack $250 \mathrm{ml}$ & $4 \times 42.5 \mathrm{ml}=170 \mathrm{ml}$
\end{tabular}

\footnotetext{
a Regarded to average volume of transfusion per unit $(=20)$ and the number of satellite packs $(=4)$
} 
$\left[\begin{array}{l}R B C \text { C Cost per } m l=(\text { Acquisitioned RBC cost }) / 250=(P C+H C+L C) / 250 \\ \text { WCpertransfusion }=\text { Wasted RBCs Volumepertransfusion } * \text { RBCs Cost per } m l\end{array}\right]$.

$H C, L C$ are constant so are removed from both arms $\left[\begin{array}{c}W C_{a}=230 * \frac{P C_{a}}{250}=0.92 P C_{a} \\ W C_{p}=42.5 * \frac{P C_{p}}{250}=0.17 P C_{p}\end{array}\right]$.

we need to prove that $\left\langle 0.92 P C_{a}>0.17 P C_{p}\right\rangle \odot$

If $P C_{p}=P C_{a}+x[1] s o 0.17 P C_{p}=0.17\left(P C_{a}+x\right) \rightarrow 0.17 P C_{p}=0.17 P C_{a}+0.17 x$

Also since $\left\{\begin{array}{l}x>0 \\ P C_{a}>0 \\ x<P C_{a}[* 1]\end{array}\right\}$ thus $\forall b>0 \quad x<b P C_{a}$

So as $\frac{0.92-0.17}{0.17}>0 \rightarrow x<((0.92-0.17) / 0.17) P C_{a}$

finally $0.92 P C_{a}>0.17 P C_{a}+0.17 x \longrightarrow 0.92 P C_{a}>0.17\left(P C_{a}+x\right)$

$\longrightarrow\left\langle 0.92 P C_{a}>0.17 P C_{p}\right\rangle \odot$

$\longrightarrow W C_{a}>W C_{p}$ or on the other words $W C_{a}=W C_{p}+f$.

Additionaly, $W_{R} C_{a}=W R C_{p}+m$.

$\left[\begin{array}{l}T C_{a}=P C_{a}+W C_{a}+W R C_{a} \\ T C_{p}=P C_{p}+W C_{p}+W R C_{p} \stackrel{[1],[3],[4]}{\longrightarrow} T C_{p}=P C_{a}+W C_{a}+W R C_{a}+\underbrace{x-(f+m)}\end{array}\right]$.

$$
\text { Therefore, if }\left\{\begin{array}{l}
x>(f+m) \longrightarrow T C_{a}<T C_{p} \\
x<(f+m) \longrightarrow T C_{a}>T C_{p}
\end{array}\right.
$$

This wasted cost was calculated for each transfusion. It is noteworthy to consider that each newborn baby underwent 4 transfusions on average during their hospital admission, therefore the cost of wasted red cells per neonate is estimated as 4 times more using adult pack versus Pedi-Pack per neonate.

Moreover, looking at Table 4, if the wasted RBCs of the adult pack to Pedi-Pack is estimated $92-68 \%$ per transfusion, it can be explained that the Pedi-Packs have $24 \%$ less wastage than the adult packs.

On the other hand, the mean number of donor-exposure rates in the adult pack system was 3.16 compared to 1 in Pedi-Pack that is equivalent to a $68.13 \%$ reduction in donor-exposure rate using Pedi-Pack.

\section{Discussion}

The total cost of the routine adult pack and the suggested Pedi-Pack was compared based on the assessment of packed RBCs utilization in three months in NICU. We proved that using Pedi-Pack instead of the routine adult pack with $<7$ days of storage in NICU can decrease the total cost of transfusion and donor-exposure rate in neonates.

The volume of our hypothetical quadruple Pedi-Pack set was similar to what was reported by Satyam et al. and Cook et al. studies $[9,10]$. However, other studies reported different values [11, 12, 15]. The mean volume of transfused RBCs per infusion in our study was determined $20 \mathrm{ml}$ that was similar to the result of Kirsten et al. study [11].

We demonstrated that usage of the quadruple PediPacks per neonate with a 20-day expiration date can decrease the donor-exposure rate from 3.16 to 1 , which 
shows a $68.13 \%$ reduction in exposure (Kerstin et al., Wood et al., Cook et al., Ibojie et al., and Straaten et al. had $33 \%, 30 \%, 15 \%, 35.1 \%, 22 \%$ reduction in DE, respectively) $[10,11,14,16,19]$. Accordingly, several studies succeeded to prove a reduction in donor-exposure rate by replacement of the alternative blood transfusion methods in NICU using diverse donor programs such as the "sterile docking device" $[18,21]$, or pack-sets with 4-8 satellite packs, by dedicating single donor units for just single neonate with increasing the expiration date of RBCs pack [14, 19, 22, 23].

Based on our results, using Pedi-Pack sets can also be associated with $24 \%$ fewer RBCs wastage compared to adult packs. It is consistent with some other studies that show using the limited donor program followed by the specific pack sets such as Pedi-Packs may contain an additional cost, but global costs decrease due to reduction in the wasted resources associated costs of risk of exposure to multiple donors and the RBCs wastage which consequently increases the cost-effectiveness [18, 21]. Hilsenrath et al. reported a $44 \%$ reduction in donorexposure rate, and despite the higher RBCs preparation cost, they could save $\$ 0.5$ per transfusion leading to an increase the cost-effectiveness [18]. Similarly, Kakaya et al. calculated $\$ 35$ for Pedi-Pack cost compared to $\$ 26$ for the one-time transfusion cost [20]. They concluded that despite the higher cost, the Pedi-Pack can be more economical because it uses for more than one transfusion. Moreover, it has less risk of exposure to the donor for infants.

Our study was limited because our cost analysis was based on the hypothetically model rather than actual usage due to the unavailability of the pediatric pack and low financial support for intentional production of this specific type of blood bag. For instance, in the calculation of the total wasted resources which consisted of wasted RBCs cost and wasted costs related to clinical complications or WRC, we were able to compare only the first one, but due to the lack of Pedi-Packs set, we were not able to compare clinical complications' cost between the two methods in reality. However, this issue was shown previously that reducing the number of exposure to donor leads to a significant impact on reducing the clinical complications [18]. So as you noticed in mathematical terms we were not able to calculate the exact specified differential cost of RBCs preparation (x) in the Pedi-Pack set and the summation of burden costs related to donor exposure risk (m) and wasted RBCs (f), and thus, it was not possible to calculate the exact total costs. However, according to the reduction in wasted RBCs with PediPack (24\% per transfusion) compared to adult pack as well as the higher rate of clinical complications due to higher number of exposure to the donor in the adult pack compared to Pedi-Pack (3.16 times) the value of " $x$ " is not expected to exceed " $\mathrm{f}+\mathrm{m}$ ", because the related costs of donor-exposure complications are generally higher than the RBCs preparation cost, so the application of new method would seem to be more cost-effective with so high possibility.

Taken together, our hypothetical model made us be able to show increased cost-effectiveness using PediPacks compared to the routine adult pack for new borne babies admitted in NICU. Our results are in line with the implementation of alternative programs in practice leading to impressive outcomes in previous studies $[17,18$, $21,22]$. The results of this study can be very helpful for policymakers especially in developing countries with a shortage of financial resources.

The next step recommended based on the result of this study, is providing the suggested Pedi-Pack by a collaboration of BTO and medical equipment companies to investigating this method in practice and establishing it as a cost-efficient method of pediatric transfusion.

\section{Conclusion}

A simple change in policy with dedicating the pediatric pack set with preserving RBCs for up to its expiry date for newborns during their hospitalization will be able to considerably reduce donor exposure rate which poses severe threats to this high-risk group Moreover, the establishment of such an effective strategy will result in keep RBCs resources, which in turn is economically important particularly in developing countries with a shortage in financial resources.

\section{Abbreviations}

RBCs: Red blood cells; BB: Blood bank; NICU: Newborn intensive care unit; Pedi-Packs: Pediatric packs; TC: Total cost; HC: Handling hospital blood bank's cost; LC: Laboratory tests cost; PC: Preparation cost; BTO: Blood transfusion organization; WC: Wasted RBCs cost; WRC: Wasted resources cost; SPSS: Statistical package for the social sciences.

\section{Acknowledgements \\ The authors would like to thank the Research Vice-Chancellor of Shiraz University of Medical Sciences for financial and approval support, Blood Bank, Health Information Management Unit, and the Center for Development of Clinical Research of Nemazee Hospital and also wish to thank Dr. Roohallah Adelian (Pediatric Department, Shiraz University of Medical Sciences) for his kind cooperation.}

\section{Authors' contributions}

$\mathrm{SH}$ and MG developed the concept for the manuscript, drafted and revised the manuscript. SM conducted data analysis and drafted the manuscript. AZ, and $A M K$, and MG cooperated in data gathering and drafted the manuscript. All authors read and approved the final manuscript.

\section{Funding}

Shiraz University of Medical Sciences supported this work financially. The funding body had no role in study design, data gathering, data analysis, data interpretation, or manuscript writing. 


\section{Availability of data and materials}

The methodology is listed in detail in the Methods section of the manuscript All data are available upon request.

\section{Declarations}

\section{Ethics approval and consent to participate}

The study protocol was approved by the Ethical Committee of Shiraz University of Medical Sciences (ID = IR.SUMS.REC.1398.995). Informed consent was obtained from all newborns' parents.

\section{Consent for publication}

Not applicable.

\section{Competing interests}

The authors declare that they have no competing interests.

\section{Author details}

${ }^{1}$ Hematology Research Center, Shiraz University of Medical Sciences, Shiraz, Iran. ${ }^{2}$ Clinical Research Development Center, Nemazee Hospital, Shiraz University of Medical Sciences, Shiraz, Iran. ${ }^{3}$ Blood Bank, Nemazee Hospital, Shiraz University of Medical Sciences, Shiraz, Iran.

Received: 26 July 2020 Accepted: 23 February 2021

Published online: 06 March 2021

\section{References}

1. Brune T, Garritsen H, Witteler R, Schlake A, Wüllenweber J, Louwen F, et al. Autologous placental blood transfusion for the therapy of anaemic neonates. Neonatology. 2002;81(4):236-43.

2. Domanović D, ZavršnikT, Vesel S. Autologous placental blood transfusion after a planned neonatal pacemaker implantation. Transfus Med. 2001;11(6):459-61.

3. Jain R, Jarosz CR, Myers TF. Decreasing blood donor exposure in the neonates by using dedicated donor transfusions. Transfus Sci. 1997;18(2):199-203.

4. Agrawal A, Goyal S. Analysis of phlebotomy blood losses in neonates in a tertiary care hospital. Indian J Child Health. 2014;1:7-11.

5. Lin JC, Strauss RG, Kulhavy JC, Johnson KJ, Zimmerman MB, Cress GA, et al. Phlebotomy overdraw in the neonatal intensive care nursery. Pediatrics. 2000;106(2):e19.

6. Bianchi M, Orlando N, Valentini CG, Papacci P, Vento G, Teofili L. Infectious complications in neonatal transfusion: narrative review and personal contribution. Transfus Apheresis Sci. 2020:59:102951.

7. Baud O, Lacaze-Masmonteil T, Monsaingeon-Lion A, Chabernaud J, Zupan V, Boithias C, et al. Single blood donor exposure programme for preterm infants: a large open study and an analysis of the risk factors to multiple donor exposure. Eur J Pediatr. 1998;157(7):579-82.

8. Del Vecchio A, Henry E, D'Amato G, Cannuscio A, Corriero L, Motta M, et al. Instituting a program to reduce the erythrocyte transfusion rate was accompanied by reductions in the incidence of bronchopulmonary dysplasia, retinopathy of prematurity and necrotizing enterocolitis. J Matern Fetal Neonatal Med. 2013;26(Sup2):77-9.

9. Arora S, Marwaha N, Dhawan HK, Rao K. Dedicated donor unit transfusions reduces donor exposure in pediatric surgery patients. Asian J Transfus Sci. 2017;11(2):124.

10. Cook S, Gunter J, Wissel M. Effective use of a strategy using assigned red cell units to limit donor exposure for neonatal patients. Transfusion. 1993;33(5):379-83.

11. Kirsten G, Kirsten C, Faber M, Collett C, Mitchell C, Bird A. Introduction of a donor exposure reduction programme for multiple-transfused very-lowbirthweight infants. South Afr Med J. 1996;86:11-1460.

12. Mangel J, Goldman M, Garcia C, Spurll G. Reduction of donor exposures in premature infants by the use of designated adenine-saline preserved split red blood cell packs. J Perinatol. 2001;21(6):363-7.

13. Strauss R, Crawford G, Elbert C, Floss A, Liesch M. Sterility and quality of blood dispensed in syringes for infants. Transfusion. 1986;26(2):163-6.
14. van Straaten HL, de Wildt-Eggen J, Huisveld IA. Evaluation of a strategy to limit blood donor exposure in high risk premature newborns based on clinical estimation of transfusion need. J Perinat Med. 2000;28(2):122-8.

15. Wang-Rodriguez J, Mannino F, Liu E, Lane T. A novel strategy to limit blood donor exposure and blood waste in multiply transfused premature infants. Transfusion. 1996;36(1):64-70.

16. Wood A, Wilson N, Skacel P, Thomas R, Tidmarsh E, Yale C, et al. Reducing donor exposure in preterm infants requiring multiple blood transfusions. Arch Dis Child Fetal Neonatal Edn. 1995;72(1):F29-33.

17. Gupta A, Patel R, Dyke M. Cost effective use of satellite packs in neonates: importance of birth weight. Arch Dis Child Fetal Neonatal Edn. 2004;89(2):F182-3.

18. Hilsenrath P, Nemechek J, Widness JA, Cordle DG, Strauss RG. Costeffectiveness of a limited-donorblood program for neonatal red cell transfusions. Transfusion. 1999;39(9):938-43.

19. Ibojie J, Greiss M, Lloyd D, Urbaniak S. Donor exposure rate to transfusion ratio: a better discriminator of improvement in neonatal transfusion practice. Transfus Med. 2003;13(5):91-287.

20. Kakaiya R, Morrison F, Rawson J, Lotz L, Martin J. Pedi-pack transfusion in a newborn intensive care unit. Transfusion. 1979;19(1):19-24.

21. Lechuga $D$, Thompson C. Cost comparison of methods for preparation of neonatal red cell aliquots. Am Soc Clin Lab Sci. 2007;20(1):29-31.

22. Prasad L, Bhatty A, Banerjee S. Donor exposure in neonatal blood transfusion-time to change strategy? Arch Dis Child. 2012;97(Suppl 1):A84.

23. Uezima CL, Barreto AM, Guinsburg R, Chiba AK, Bordin JO, Barros MMO, et al. Reduction of exposure to blood donors in preterm infants submitted to red blood cell transfusions using pediatric satellite packs. Rev Paul Pediatr. 2013;31(3):285-92.

24. Boriboonhirunsarn D, Chaopothong P, Jirasawas T. Blood transfusion in elective abdominal gynecologic surgery. J Gynecol Surg. 2017:33(6):231-5.

25. Chalya PL, Mbunda F, Mabula JB, Massinde AN, Kihunrwa A, Gilyoma $J M$. Blood transfusion practice in surgery at Bugando Medical Centre in northwestern Tanzania. Tanzan J Health Res. 2016;18(1).

26. Gamage C, Pratheepan P, Sivaganesh S. Rationale for blood request: cross match versus group and screen. Sri Lanka J Surg. 2014;31(3):24.

27. Golpayegani M, Akramipour R, Zanganeh S, Rezayi M, Yousefi H, Faranoush M. Study of blood products utilization in major Departments of Imam Reza Hospital, Kermanshah, Iran. Iran J Blood Cancer. 2014;6(4):8-203.

28. Kafi-Abad SA, Omidkhoda A, Pourfatollah AA. Analysis of hospital blood components wastage in Iran (2005-2015). Transfus Apheres Sci. 2019;58(1):34-8.

29. Khazaei A, Jahromi AS, Khoshfetrat M, Behnampoor M, Jahandideh M. Monitoring blood consumption with emphasis on MSBOS table in Educational Hospitals Zahedan, Iran, 2014. J Res Med Dental Sci. 2018:6(2):574-7.

30. Lookzadeh MH, Adhami F, Shadkam MN, Mirjalili SR, Sheikhpour E. The frequency of packed red blood cells transfusion in preterm infants admitted to NICU of Shahid Sadoughi Hospital during 2016. Iran J Pediatr Hematol Oncol. 2019

31. Tahmasebi A, Khedri S, Khosravi S, Miri-Moghaddam E. Determination of blood components utilization pattern in Zahedan City, Southeast of Iran. Modern Care J. 2020;17(1).

32. Strauss $R$, Burmeister $L$, James T, Miller J, Johnson $K$, Bell $E$, editors. A randomized trial of fresh versus stored RBCs for neonatal transfusions. Transfusion. 1994

33. Strauss R, Burmeister $L$, Johnson K, James T, Miller J, Cordle D, et al. AS-1 red cells for neonatal transfusions: a randomized trial assessing donor exposure and safety. Transfusion. 1996;36(10):873-8.

34. Forbes J, Anderson M, Anderson GF, Bleecker G, Rossi E, Moss G. Blood transfusion costs: a multicenter study. Transfusion. 1991;31(4):318-23.

\section{Publisher's Note}

Springer Nature remains neutral with regard to jurisdictional claims in published maps and institutional affiliations. 